\title{
UTILIZAÇÃO DE DIFERENTES TIPOS DE POLICLORETOS DE ALUMÍNIO PARA PURIFICAÇÃO DE HIDROLISADO DE BAGAÇO DE CANA ATRAVÉS DA TÉCNICA DE COAGULAÇÃO E FLOCULAÇÃO
}

\author{
Leonardo de Lima Noronha, Christiane Reis Fonseca*, Cássia Cavalcanti da Silva, Messias Borges Silva e Luís Fernando \\ Figueiredo Faria \\ Departamento de Engenharia Química, Escola de Engenharia de Lorena, Universidade de São Paulo, CP 116, 12602-810 Lorena \\ - SP, Brasil
}

Recebido em 2/12/09; aceito em 27/4/10; publicado na web 9/8/10

\begin{abstract}
USE OF DIFFERENT KINDS OF ALUMINUM POLYCHLORIDE IN THE SUGARCANE BAGASSE HYDROLYZATE PURIFICATION THROUGH COAGULATION AND FLOCCULATION TECHNICS. In order to investigate the action of the flocculating agents Panfloc and Panclar a full factorial design $2^{3}$ and a Central Composite design $2^{2}$ were carried out. The control variables were the flocculant concentration, $\mathrm{pH}$ and temperature. The response variables were phenolic compounds reduction and spectral area reduction. The best conditions of treatment was hydrolyzate at $\mathrm{pH} 9$ for both coagulants, but the use of Panfloc was more effective in the phenolic compounds reduction (73.9\%) and spectral area reduction (65.8\%).
\end{abstract}

Keywords: hydrolyzate; coagulation; aluminum polychloride.

\section{INTRODUÇÃO}

Materiais lignocelulósicos sob forma de resíduos agrícolas e florestais são acumulados anualmente, no mundo, em grandes quantidades. Devido a sua natureza renovável e a seu baixo custo, estes materiais têm sido utilizados amplamente como matéria-prima para geração de energia, ração animal e principalmente como fonte de carboidratos para processos de bioconversão. ${ }^{1}$ Quando hidrolisados estes materiais lignocelulósicos liberam açúcares (D-glicose, Dgalactose, D-manose, D-xilose e L-arabinose) e diversos compostos derivados dos açúcares e da lignina (furfural, hidroximetilfurfural, ácido acético, ácido siríngico, $p$-hidroxibenzoico, vanilina, e outros compostos). Os hidrolisados lignocelulósicos podem ser utilizados para a produção de xilitol, etanol e outros produtos úteis. Entretanto, os subprodutos do açúcar e da lignina afetam de forma negativa a fermentação deste meio. ${ }^{2}$

O Brasil possui uma grande vocação para a agricultura sucroalcooleira que, aliada às suas dimensões continentais, faz dele o maior produtor de cana-de-açúcar do mundo, sendo estimada, para a safra 2008/2009, uma produção de 572,5 milhões de toneladas, superior em $15,5 \%$ à safra anterior. ${ }^{3}$ Mesmo gerando riquezas e desenvolvimento para o país, tais números trazem como consequência um grande problema, que é a geração aproximada de 128 milhões de toneladas de bagaço ao ano. Em sua maior parte, este subproduto é aproveitado pela própria indústria, entretanto, ainda há um excedente que preocupa os ambientalistas, principalmente devido ao risco de combustão espontânea. ${ }^{4}$

Esta grande parcela não utilizada do bagaço de cana-de-açúcar apresenta grande potencial de aproveitamento devido a sua composição química (celulose, hemicelulose e lignina) uma vez que, através da hidrólise ácida é possível extrair até $80 \%$ das pentoses da fração hemicelulósica em forma de xilose, ${ }^{5}$ um carboidrato utilizado em processos de bioconversão. Através da fermentação da xilose são obtidos produtos de alto valor agregado como o xilitol e também etanol. ${ }^{6}$

Diversos trabalhos vêm sendo desenvolvidos com o objetivo de se avaliar a produção de etanol a partir do bagaço da cana utilizan-

\footnotetext{
*e-mail: christiane@dequi.eel.usp.br
}

do processo de bioconversão por leveduras da xilose contida em diferentes hidrolisados hemicelulósicos, o que poderia aumentar em até $30 \%$ a quantidade de etanol produzida, sem a expansão da área plantada. ${ }^{7}$

Embora promissor, o processo fermentativo de produção de xilitol e etanol a partir do hidrolisado hemicelulósico também apresenta limitações, principalmente quanto à produtividade, devido à presença de compostos inibidores do metabolismo microbiano. ${ }^{8}$

A fim de melhorar a fermentabilidade dos hidrolisados vários métodos de purificação têm sido estudados como extração por solventes orgânicos, tratamento com $\mathrm{Ca}(\mathrm{OH})_{2}$, evaporação, tratamento com sulfito, resinas de troca iônica, tratamento enzimático, tratamento com zeólitas e tratamento com carvão ativado. ${ }^{9}$

No presente trabalho foi estudado o tratamento do hidrolisado de bagaço de cana-de-açúcar pelo método de coagulação e floculação de impurezas coloidais utilizando dois diferentes tipos de policloreto de alumínio. O planejamento de experimentos começou pela definição das variáveis mais importantes no processo em questão e a avaliação de sua influência sobre a resposta de interesse. Então, pode-se realizar a técnica de planejamento de experimentos escolhida, neste caso um fatorial completo do tipo $2^{3}$ e delineamento composto central rotacional (DCCR) $2^{2}$.

\section{PARTE EXPERIMENTAL}

\section{Materiais}

Bagaço de cana-de-açúcar proveniente da Usina Açucareira Furlan S/A (SP). Óxido de cálcio comercial. Coagulantes: PANFLOC TE HP e PANCLAR P1010, gentilmente cedidos pela Pan-Americana S. A. Indústrias Químicas.

\section{Obtenção do hidrolisado hemicelulósico}

O hidrolisado foi obtido por hidrólise ácida do bagaço de cana em reator de aço inoxidável AISI 316 com volume útil de $250 \mathrm{~L}$, equipado com camisa de óleo térmico para aquecimento indireto. $\mathrm{O}$ reator foi operado em regime descontínuo, empregando-se as seguintes condições de hidrólise: temperatura de $121^{\circ} \mathrm{C}$; tempo 
de reação de 10 min; 100 mg de ácido sulfúrico (98\%) para 1 g de bagaço (matéria seca) e uma proporção entre massa de bagaço e volume de solução ácida de 1:10. O hidrolisado foi centrifugado e armazenado em câmara fria.

\section{Coagulação e floculação seletiva de impurezas coloidais}

O hidrolisado foi submetido à coagulação e floculação das impurezas coloidais a fim de se determinar a melhor condição experimental para maior remoção de impurezas e se obter, assim, o hidrolisado tratado. Primeiramente foi utilizado um planejamento fatorial completo $2^{3}$ com três repetições no ponto central. As variáveis analisadas foram: $\mathrm{pH}$ (ajustado com óxido de cálcio) (A), temperatura (B) e concentrações (C) do coagulante. Após o ajuste do $\mathrm{pH}$, o hidrolisado foi filtrado a vácuo para posterior adição do agente coagulante. $\mathrm{O}$ tempo de agitação foi fixado em 1 min de agitação rápida e 15 min de agitação lenta. ${ }^{10}$ Após a análise dos resultados do primeiro tratamento estatístico as variáveis mais significativas foram determinadas. A seguir, foi proposto um segundo planejamento experimental, desta vez do tipo delineamento composto central rotacional (DCCR) $2^{2}$ com quatro experimentos nos pontos axiais e três no ponto central.

\section{Métodos analíticos}

\section{Determinação do teor de carboidratos}

A determinação do teor de carboidratos no hidrolisado foi feita por HPLC. Uma alíquota de $5 \mathrm{~mL}$ da solução foi filtrada em membranas de $0,45 \mu \mathrm{m}$, cartucho Sep Pak C18 e analisada em um cromatógrafo Shimadzu modelo CR 7A, empregando um detector de índice de refração Shimadzu RID-6A e uma coluna Aminex HPX $87 \mathrm{H}$ (300 x 7,8 mm, BIO-RAD). Como fase móvel foi empregado $\mathrm{H}_{2} \mathrm{SO}_{4} 0,005 \mathrm{~mol} \mathrm{~L}^{-1}$ com fluxo de $0,6 \mathrm{~mL} \mathrm{~min}^{-1}$ a $45^{\circ} \mathrm{C}$.

\section{Determinação do teor de furfural e hidroximetilfurfural}

Os produtos de decomposição dos açúcares (furfural e hidroximetilfurfural) presentes no hidrolisado ácido foram analisados por HPLC utilizando-se um cromatógrafo Shimadzu modelo CR-7A com detector de UV visível, marca Shimadzu modelo SPD-10ª empregando uma coluna RP-18 (C-18) de 125 x 4 mm (Hawlett-Packard) e como fase móvel, solução de acetonitrila/água 1:8 (v/v) com $1 \%$ de ácido acético, num fluxo de $0,8 \mathrm{~mL} \mathrm{~min}^{-1}$ a $25^{\circ} \mathrm{C}$.

\section{Determinação de produtos de decomposição da lignina}

Para determinação de compostos fenólicos (lignina solúvel), foi utilizado o método Klason onde uma alíquota de $0,5 \mathrm{~mL}$ do hidrolisado obtido foi pré-diluída e alcalinizada com $\mathrm{NaOH} 6,5 \mathrm{~mol} \mathrm{~L}^{-1}$ até atingir $\mathrm{pH} 12,5$. Posteriormente, foi vertida para um balão volumétrico de $100 \mathrm{~mL}$ e o volume foi completado. A absorbância desta solução foi determinada por espectroscopia UV em um comprimento de onda de $280 \mathrm{~nm}$. Utilizou-se água destilada com pH igual a 12,5 como referência. ${ }^{11}$

A concentração de lignina solúvel foi determinada a partir da Equação 1.

$$
\mathrm{C}_{\text {lig }}=4,187 \times 10^{-2}\left(\mathrm{~A}_{\operatorname{lig} 280}-\mathrm{A}_{\mathrm{pd} 280}\right)-3,279 \times 10^{-4}
$$

\section{Determinação da área espectral}

Através do espectrofotômetro Varian, modelo Cary 50, foi feita uma varredura no espectro visível (comprimento de onda de 400 a $700 \mathrm{~nm}$ ) utilizando uma alíquota de $1 \mathrm{~mL}$ do hidrolisado após ser purificado, diluído em balão volumétrico de $25 \mathrm{~mL}$. A área abaixo da curva de absorbância é calculada e representada em termos de unidades de área (u.a).

\section{RESULTADOS E DISCUSSÃO}

\section{Obtenção do hidrolisado hemicelulósico}

Duas bateladas de hidrólise foram realizadas para a execução deste trabalho, sendo que $18,36 \mathrm{~kg}$ de bagaço seco foram utilizados. $\mathrm{Na}$ primeira batelada foram extraídos $105 \mathrm{~L}$ de hidrolisado e, na última, $100 \mathrm{~L}$ desta solução.

Vários compostos são liberados através da quebra das ligações entre os monômeros de açúcar da cadeia polimérica da hemicelulose e celulose; isto se deve à utilização de ácido sulfúrico durante a hidrólise. Entre os compostos liberados estão os açúcares (xilose, glicose e arabinose), oligômeros, furfural, hidroximetilfurfural, ácido acético e, ainda, íons de metais pesados provenientes da corrosão dos equipamentos e do solo.

Os volumes das duas bateladas foram armazenados em câmara fria. Devido ao período de estocagem, o hidrolisado foi homogeneizado e filtrado a vácuo, retirando-se algumas impurezas que precipitaram. O mesmo foi caracterizado e os teores dos principais compostos foram determinados e estão apresentados na Tabela 1.

Tabela 1. Composição e características físicas do hidrolisado hemicelulósico original

\begin{tabular}{lc}
\hline Parâmetros & Hidrolisado \\
\hline $\mathrm{pH}$ & 0,87 \\
Glicose $(\mathrm{g} / \mathrm{L})$ & 1,34 \\
Xilose $(\mathrm{g} / \mathrm{L})$ & 15,76 \\
Arabinose $(\mathrm{g} / \mathrm{L})$ & 2,03 \\
Acido Acético $(\mathrm{g} / \mathrm{L})$ & 3,24 \\
Furfural $(\mathrm{g} / \mathrm{L})$ & 0,02 \\
Hidroximetilfurfural (g/L) & 0,06 \\
Compostos Fenólicos (g/L) & 4,25 \\
Área Espectral (u.a.)* & 12,94 \\
\hline
\end{tabular}

*(u.a) unidade de área

Observa-se a partir da Tabela 1 que a xilose é o açúcar predominante, sendo esta uma característica desejável para as bioconversões a partir deste carboidrato, uma vez que a presença de glicose pode inibir o metabolismo da xilose nas leveduras, ${ }^{12}$ dependendo da concentração dessa hexose no meio de fermentação. ${ }^{13}$

A fermentação de hidrolisados de materiais lignocelulósicos não purificados é caracterizada por cinética lenta e limitada produtividade e rendimentos, em comparação com aqueles de açúcares comerciais ou hidrolisados purificados. ${ }^{14}$

A presença de compostos tóxicos inibitórios à atividade fermentativa está em valores significativos em relação à massa seca, como os compostos fenólicos $(15,92 \%)$, o ácido acético $(12,14 \%)$, o furfural $(0,08 \%)$ e o hidroximetilfurfural $(0,23 \%)$.

De acordo com a literatura, as concentrações desses compostos nos hidrolisados hemicelulósicos variam em função do tipo de material lignocelulósico e das condições hidrolíticas empregadas para a extração da fração hemicelulósica. ${ }^{15}$ As pentoses e hexoses degradam formando furfural e hidroximetilfurfural, respectivamente. A presença desses compostos no hidrolisado confirma a parcial degradação desses açúcares.

A obtenção de um hidrolisado com 15,76 g/L de xilose representa uma hidrólise aceitável quando comparada com dados da literatura. ${ }^{16}$ Devido à limitação de descarga do reator, a concentração de xilose foi menor que o esperado, pois a válvula possui uma pequena abertura que impossibilita a retirada do hidrolisado, o qual fica absorvido na celulignina residual. As condições de armazenamento também podem afetar este índice. 


\section{Coagulação e floculação de impurezas coloidais}

O hidrolisado obtido foi submetido à coagulação e floculação de impurezas coloidais, sendo que cada agente coagulante foi analisado separadamente. De acordo com os níveis e parâmetros estabelecidos no primeiro planejamento estatístico, conforme a Tabela 2 foram realizados 11 experimentos. As amostras foram analisadas quanto às reduções de compostos fenólicos totais e área espectral, e os resultados são apresentados nas Tabelas 3 e 4.

Tabela 2. Níveis e parâmetros utilizados no primeiro planejamento estatístico

\begin{tabular}{lccc}
\hline Variáveis & \multicolumn{3}{c}{ Níveis } \\
\hline $\mathrm{pH}$ & -1 & 0 & +1 \\
Temperatura $\left({ }^{\circ} \mathrm{C}\right)$ & 5 & 7 & 9 \\
Coagulante $(\mathrm{mg} / \mathrm{L})$ & 0 & 40 & 55 \\
\hline
\end{tabular}

Tabela 3. Condições experimentais do planejamento fatorial completo e variáveis de resposta com o uso de PANCLAR

\begin{tabular}{cccccc}
\hline Ensaio & $\mathrm{pH}$ & $\begin{array}{c}\text { Temp. } \\
\left({ }^{\circ} \mathrm{C}\right)\end{array}$ & $\begin{array}{c}\text { Panclar } \\
(\mathrm{ppm})\end{array}$ & $\begin{array}{c}\text { Compostos } \\
\text { fenólicos }(\mathrm{g} / \mathrm{L})\end{array}$ & $\begin{array}{c}\text { Área espectral } \\
\text { (u. a. })^{*}\end{array}$ \\
\hline 1 & 5 & 25 & 0 & 2,33 & 20,15 \\
2 & 9 & 25 & 0 & 1,54 & 6,26 \\
3 & 5 & 55 & 0 & 2,70 & 15,87 \\
4 & 9 & 55 & 0 & 1,47 & 6,51 \\
5 & 5 & 25 & 20 & 2,65 & 19,64 \\
6 & 9 & 25 & 20 & 1,44 & 6,46 \\
7 & 5 & 55 & 20 & 2,50 & 15,06 \\
8 & 9 & 55 & 20 & 1,44 & 6,32 \\
9 & 7 & 40 & 10 & 1,85 & 10,48 \\
10 & 7 & 40 & 10 & 1,80 & 17,76 \\
11 & 7 & 40 & 10 & 1,74 & 5,83 \\
\hline
\end{tabular}

*(u.a) unidade de área.

Tabela 4. Condições experimentais do planejamento fatorial completo e variáveis de resposta com o uso de PANFLOC

\begin{tabular}{cccccc}
\hline Ensaio & $\mathrm{pH}$ & $\begin{array}{c}\text { Temp. } \\
\left({ }^{\circ} \mathrm{C}\right)\end{array}$ & $\begin{array}{c}\text { Panfloc } \\
(\mathrm{ppm})\end{array}$ & $\begin{array}{c}\text { Compostos } \\
\text { fenólicos (g/L) }\end{array}$ & $\begin{array}{c}\text { Área espectral } \\
\text { (u. a. })^{*}\end{array}$ \\
\hline 1 & 5 & 25 & 0 & 2,22 & 22,55 \\
2 & 9 & 25 & 0 & 1,21 & 6,92 \\
3 & 5 & 55 & 0 & 2,44 & 16,78 \\
4 & 9 & 55 & 0 & 1,26 & 7,99 \\
5 & 5 & 25 & 20 & 2,53 & 23,54 \\
6 & 9 & 25 & 20 & 1,22 & 7,88 \\
7 & 5 & 55 & 20 & 2,44 & 14,67 \\
8 & 9 & 55 & 20 & 1,31 & 6,09 \\
9 & 7 & 40 & 10 & 1,56 & 8,02 \\
10 & 7 & 40 & 10 & 1,62 & 9,06 \\
11 & 7 & 40 & 10 & 1,75 & 7,69 \\
\hline
\end{tabular}

* (u.a) unidade de área

Ao analisar os dados obtidos com o software MINITAB foram construídos os diagramas de Pareto para os compostos fenólicos e variação da área espectral para o PANCLAR (Figuras 1 e 2) e para o PANFLOC (Figuras 3 e 4). Com o uso do PANCLAR, a maior significância da variável $\mathrm{pH}$ em relação a compostos fenólicos foi evidenciada e, também, a ação combinada das 3 variáveis mostrou significância bem próxima ao limite. Com relação à remoção de área espectral, nenhuma variável apresentou significância estatística.

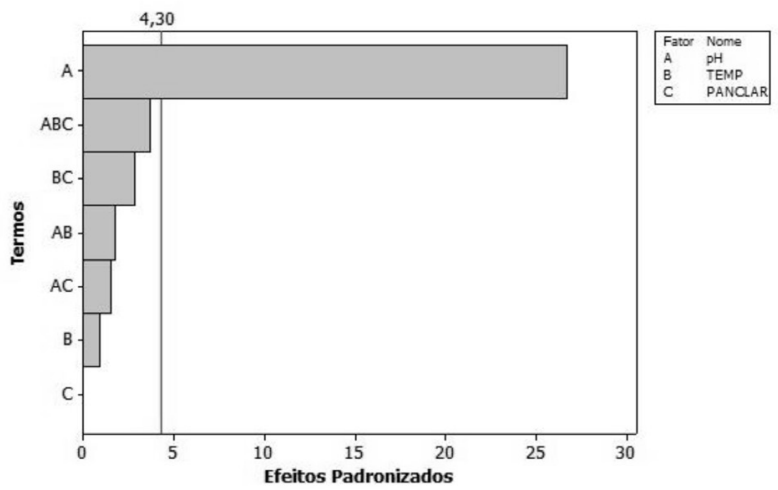

Figura 1. Diagrama de Pareto em função dos compostos fenólicos para o PANCLAR

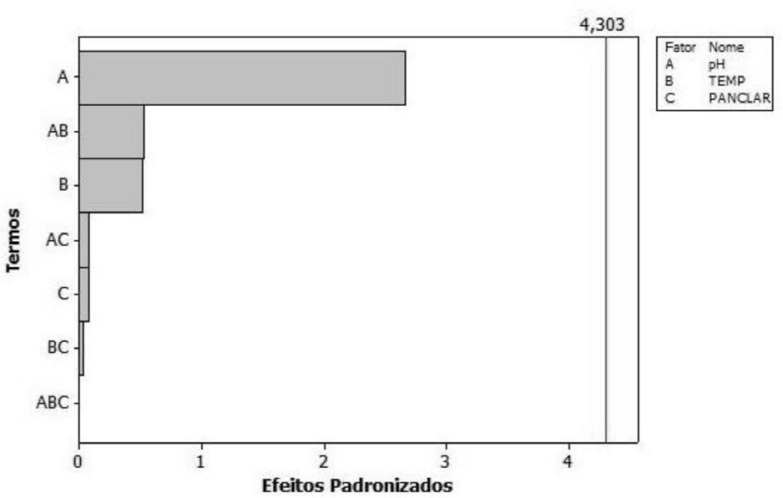

Figura 2. Diagrama de Pareto da variação da área espectral para o PANCLAR

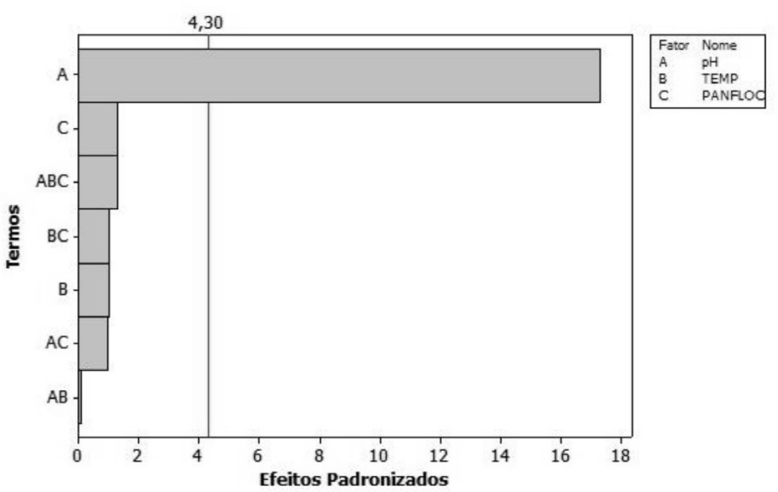

Figura 3. Diagrama de Pareto em função dos compostos fenólicos para o PANFLOC

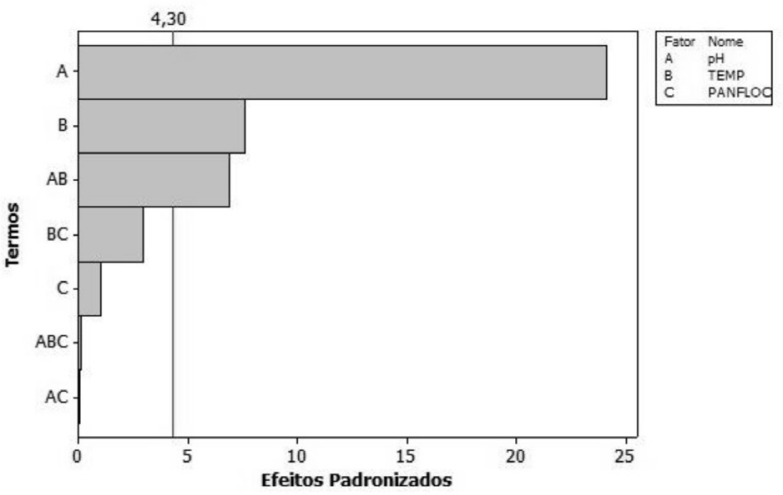

Figura 4. Diagrama de Pareto da variação da área espectral para o PANFLOC 
Para o outro agente coagulante, PANFLOC, concluiu-se que o fator mais influente na redução de compostos fenólicos também foi o pH. Já nos resultados para a remoção de área espectral novamente o pH apresentou maior significância estatística, seguido da temperatura para as variáveis isoladas.

Para o PANCLAR, considerando-se a faixa ótima de $\mathrm{pH}$, o aumento na concentração favoreceu a redução de compostos fenólicos. Deste modo, a nova faixa de concentração para este coagulante a ser avaliada no DCCR foi ampliada, usando como limite superior 50 mg/L (Tabela 5). O mesmo ocorreu para o PANFLOC, contudo, na faixa de concentração estudada inicialmente, sua influência na redução de compostos fenólicos apresentou menor variabilidade, assim, optou-se por manter o zero como limite mínimo ampliando-se o limite máximo para $40 \mathrm{mg} / \mathrm{L}$. Na Tabela 5 são apresentadas as variáveis de controle e seus respectivos níveis usados nos dois DCCR, um para cada coagulante em estudo.

Tabela 5. Níveis e parâmetros utilizados no segundo tratamento estatístico (DCCR)

\begin{tabular}{lccccc}
\hline Variáveis & $-1,41$ & -1 & 0 & +1 & $+1,41$ \\
\hline $\mathrm{pH}$ & 6,5 & 7,1 & 8,5 & 9,9 & 10,5 \\
$\mathrm{PC}(\mathrm{mg} / \mathrm{L})$ & 10 & 15,8 & 30 & 4,2 & 50 \\
$\mathrm{pH}$ & 6,5 & 7,1 & 8,5 & 9,9 & 10,5 \\
$\mathrm{PF}(\mathrm{mg} / \mathrm{L})$ & 0 & 5,8 & 20 & 34,2 & 40 \\
\hline
\end{tabular}

De acordo com o DCCR, planejamento que utiliza pontos axiais além dos pontos centrais, novamente foram realizados 11 experimentos para cada coagulante testado. Os resultados obtidos após as análises de compostos fenólicos e área espectral são mostrados nas Tabelas 6 e 7.

Tabela 6. Matriz do DCCR e resultados de teor de compostos fenólicos e área espectral para o PANCLAR

\begin{tabular}{lcccc}
\hline Ensaio & $\mathrm{pH}$ & $\begin{array}{c}\text { Panclar } \\
(\mathrm{ppm})\end{array}$ & $\begin{array}{c}\text { Compostos } \\
\text { fenólicos }(\mathrm{g} / \mathrm{L})\end{array}$ & $\begin{array}{c}\text { Área espectral } \\
\text { (u. a.) }\end{array}$ \\
\hline 1 & 7,1 & 15 & 1,23 & 19,65 \\
2 & 9,9 & 15 & 1,22 & 4,85 \\
3 & 7,1 & 44 & 1,26 & 18,26 \\
4 & 9,9 & 44 & 1,29 & 4,77 \\
5 & 6,5 & 30 & 1,77 & 17,29 \\
6 & 10,5 & 30 & 1,38 & 5,94 \\
7 & 8,5 & 10 & 1,22 & 3,72 \\
8 & 8,5 & 50 & 1,22 & 2,65 \\
9 & 8,5 & 30 & 1,27 & 3,70 \\
10 & 8,5 & 30 & 1,21 & 2,15 \\
11 & 8,5 & 30 & 1,25 & 2,80 \\
\hline
\end{tabular}

* (u.a) unidade de área.

Através do MINITAB foi realizado o tratamento estatístico dos resultados, a partir dos quais foram obtidos os modelos matemáticos capazes de descrever as características de redução de compostos fenólicos (Equações 2 e 4) e área espectral (Equações 3 e 5) em função das alterações tanto de $\mathrm{pH}$ como de policloreto de alumínio. Para os modelos que analisam compostos fenólicos foram gerados gráficos de curva de contorno para o PANCLAR (Figura 5 ) e para o PANFLOC (Figura 6).

Baseado na análise de todos os resultados obtidos com o segundo tratamento estatístico e pela análise das curvas de contorno foi possível confirmar que a região indicativa de menores concentrações de fenólicos totais e menores valores de área espectral encontra-se em $\mathrm{pH}$ alcalino, tendendo ao valor 9 .
Tabela 7. Matriz do DCCR e resultados de teor de compostos fenólicos e área espectral para o PANFLOC

\begin{tabular}{ccccc}
\hline Ensaios & pH & $\begin{array}{c}\text { Panfloc } \\
(\mathrm{ppm})\end{array}$ & $\begin{array}{c}\text { Compostos } \\
\text { fenólicos }(\mathrm{g} / \mathrm{L})\end{array}$ & $\begin{array}{c}\text { Área espectral } \\
\text { (u. a.)* }\end{array}$ \\
\hline 1 & 7,1 & 5,8 & 1,26 & 14,41 \\
2 & 9,9 & 5,8 & 1,11 & 4,43 \\
3 & 7,1 & 34,2 & 1,59 & 13,63 \\
4 & 9,9 & 34,2 & 1,18 & 5,09 \\
5 & 6,5 & 20 & 1,67 & 11,08 \\
6 & 10,5 & 20 & 1,26 & 7,70 \\
7 & 8,5 & 0 & 1,25 & 3,01 \\
8 & 8,5 & 40 & 1,17 & 3,36 \\
9 & 8,5 & 20 & 1,22 & 3,84 \\
10 & 8,5 & 20 & 1,18 & 3,81 \\
11 & 8,5 & 20 & 1,15 & 3,02 \\
\hline
\end{tabular}

* (u.a) unidade de área

$[\mathrm{CF}]=1,242-0,067_{*} \mathrm{pH}+0,011_{*} \mathrm{PC}+0,130_{*} \mathrm{pH}^{2}-0,049_{*} \mathrm{PC}^{2}$ $+0,008_{*} \mathrm{pH}_{*} \mathrm{PC}$

$[\mathrm{AE}]=2,883-5,542_{*} \mathrm{pH}-0,373{ }_{*} \mathrm{PC}+5,486_{*} \mathrm{pH}^{2}+1,272_{*} \mathrm{PC}^{2}$ $+0,328_{*} \mathrm{pH}_{*} \mathrm{PC}$

$[\mathrm{CF}]=1,183-0,145_{*} \mathrm{pH}+0,036_{*} \mathrm{PF}+0,128_{*} \mathrm{pH}^{2}-0,001_{*} \mathrm{PF}^{2}$ $-0,066_{*} \mathrm{pH}_{*} \mathrm{PF}$

As concentrações dos agentes coagulantes, nos níveis estudados, apresentaram pouca variabilidade nos resultados. Considerando a redução de compostos fenólicos para ambos coagulantes, o mais eficiente foi o PANFLOC, que no melhor $\mathrm{pH}$ de trabalho (ensaio 2, Tabela 7), variou de 4,25 para $1,11 \mathrm{mg} / \mathrm{L}$, o que representa uma redução de $73,9 \%$. Com relação à diminuição de área espectral, o PANCLAR foi mais eficiente, variando de 12,94 para 2,15 u.a., representando uma redução de 83,4\%, também em pH alcalino (ensaio 10, Tabela 7).

Contudo, devido ao caráter inibitório dos compostos fenólicos e pelo fato da área espectral ser somente um indicativo de cor, pode-se afirmar que o agente coagulante PANFLOC foi o mais eficiente por apresentar a maior remoção de fenólicos. Portanto, a melhor condição experimental para os níveis estudado foi $\mathrm{pH}=9$, temperatura de 25 ${ }^{\circ} \mathrm{C}$ e concentração de PANFLOC igual a $5,8 \mathrm{mg} / \mathrm{L}$.

$[\mathrm{AE}]=3,556-2,913_{*} \mathrm{pH}+0,047, \mathrm{PF}+3,694_{*} \mathrm{pH}^{2}+0,590_{*} \mathrm{PF}^{2}$ $+0,357_{*} \mathrm{pH}_{*} \mathrm{PF}$
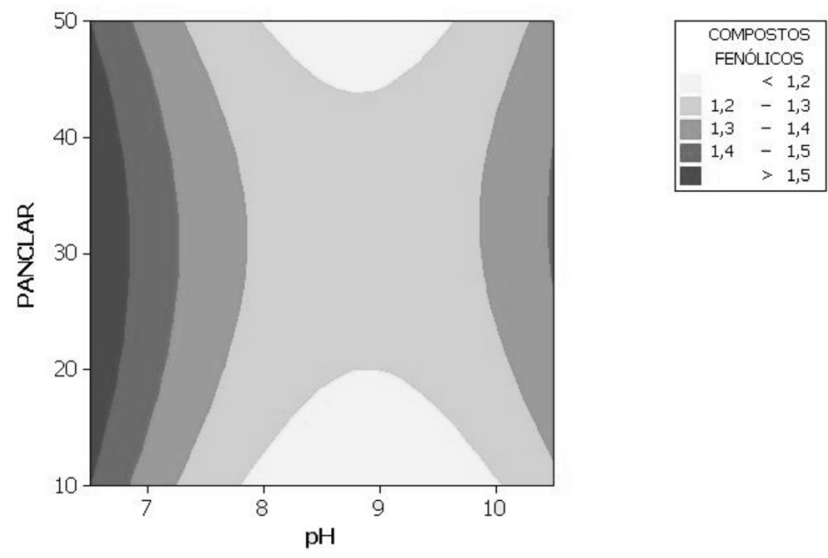

Figura 5. Curvas de contorno em função dos compostos fenólicos para o PANCLAR 


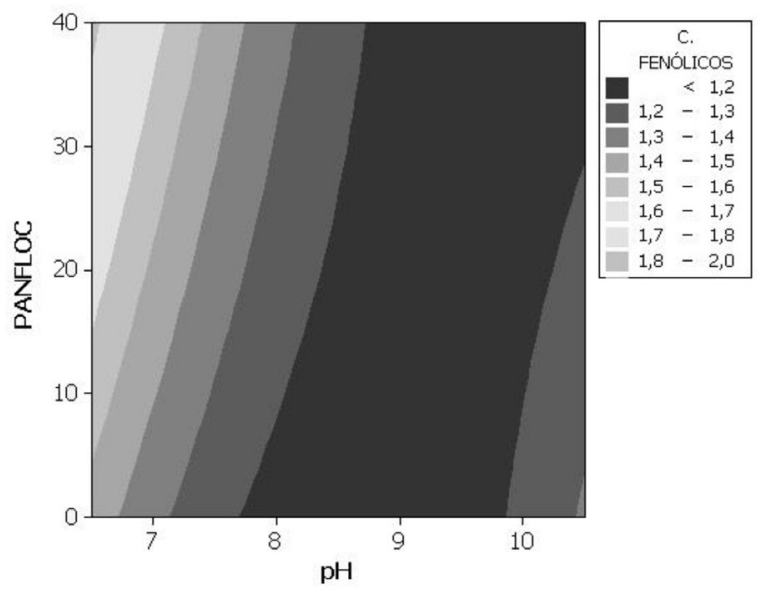

Figura 6. Curvas de contorno em função dos compostos fenólicos para o PANFLOC

Apesar dos agentes coagulantes testados causarem baixa variabilidade nos resultados dentro dos níveis estudados, não significa que não foram eficientes. Foi possível observar que a faixa de $\mathrm{pH}$ ótima para as reduções estudadas está próxima de 9. Portanto, com esse valor já delimitado, será possível estudar a concentração do coagulante em níveis mais ampliados na busca de uma condição mais otimizada para uso do PANFLOC.

\section{CONCLUSÕES}

O planejamento fatorial foi de grande importância para delinear estatisticamente a melhor condição de remoção de compostos fenólicos e área espectral.

Os dois coagulantes testados foram estatisticamente pouco significativos nos resultados obtidos, sendo que o PANFLOC foi o que apresentou melhores resultados, conseguindo remover $73,9 \%$ de compostos fenólicos e $65,8 \%$ de área espectral na melhor condição experimental.

Como o pH igual a 9 foi o fator mais significante na purificação do hidrolisado, a variável $\mathrm{pH}$ poderá permanecer constante, e o estudo das melhores condições de concentração poderá ser realizado a fim de avaliar a significância dessa variável nas remoções, tanto de compostos fenólicos quanto de área espectral em outros níveis.

\section{NOMENCLATURA}

$\mathrm{AE}=$ Área espectral.

$\mathrm{C}_{\mathrm{lig}}=$ Concentração de compostos fenólicos $\left(\mathrm{g} \mathrm{L}^{-1}\right)$.
$\mathrm{A}_{\operatorname{lig} 280}=$ Absorbância em $280 \mathrm{~nm}$.

$\mathrm{A}_{\mathrm{pd} 280}=\mathrm{c}_{1} \varepsilon_{1}+\mathrm{c}_{2} \varepsilon_{2}$ : absorbância, em $280 \mathrm{~nm}$, dos produtos de decomposição dos açúcares (furfural e hidroximetilfurfural), cujas concentrações $c_{1}$ e $c_{2}$ foram determinadas previamente e $\varepsilon_{1}$ e $\varepsilon_{2}$ foram determinados por espectrometria de UV e valem, respectivamente, 146,85 e $114,00 \mathrm{~L} \mathrm{~g}^{-1} \mathrm{~cm}^{-1}$ ).

$\mathrm{CF}=$ Compostos fenólicos.

$\mathrm{DCCR}=$ delineamento composto central rotacional.

$\mathrm{PC}=$ PANCLAR P1010.

$\mathrm{PF}=$ PANFLOC TE HIPER PLUS.

\section{MATERIAL SUPLEMENTAR}

Está disponível em http://quimicanova.sbq.org.br, na forma de arquivo .PDF, com acesso livre.

\section{REFERÊNCIAS}

1. Kuhad, R. C.; Singh, A.; Critical Reviews in Biotechnology 1993, 13,151 .

2. Mussato, S. I.; Santos, J. C.; Roberto, I. C. J.; Chem. Technol. Biotechnol. 2004, 79, 590.

3. http://www.agricultura.gov.br, acessada em Maio 2009.

4. Sun, J. X.; Sun, R.; Sun, X-F.; Su, Y.; Carbohydr. Res. 2004, 39, 291.

5. Aguilar, R.; Ramirez, J. A.; Garrote, G.; Vázquez, M.; Journal of Food Engineering 2002, 55, 309.

6. Aristidou, A.; Penttilä, M.; Curr. Opin. Biotechnol. 2000, 11, 187.

7. Amartey, S.; Jeffries, T.; Journal of Microbiology and Biotechnology 1996, 12, 281.

8. Lohmeier-Vogel, E. M.; Sopher, C. R.; Lee, H.; J. Ind. Microbiol. Biotechnol. 1998, 20, 75.

9. Miyafuji, H.; Danner, H.; Neureiter, M.; Thomasser, C.; Bvochora, J.; Szolar, O.; Braun, R.; Enzyme Microb. Technol. 2002, 32, 396.

10. Koblitz, M. G. B.; Dissertação de Mestrado, Universidade de Campinas, Brasil, 1998.

11. Rocha, G. J. M.; Tese de Doutorado, Universidade de São Paulo, Brasil, 2000.

12. Preziosi-Belloy, L.; Nolleau, V.; Navarro, J. M.; Enzyme Microb. Technol. 2007, 21, 124.

13. Silva, D. D. V.; Felipe, M. G. A.; Rorigues, R. C. L. B.; VI Seminário Brasileiro de Tecnologia Enzimática, Rio de Janeiro, Brasil, 2004.

14. Villarreal, M. L. M.; Prata, A. M. R.; Felipe, M. G. A.; Almeida e Silva, J. B.; Enzyme Microb. Technol. 2006, 40, 17.

15. Silva, S. S.; Felipe, M. G. A.; Silva, J. B. A.; Prata, A. M. R.; Process Biochem. 1998, 33, 63.

16. Cunha, M. A. A.; Tese de Doutorado, Universidade de São Paulo, Brasil, 2006. 


\section{UTILIZAÇÃO DE DIFERENTES TIPOS DE POLICLORETOS DE ALUMÍNIO PARA PURIFICAÇÃO DE HIDROLISADO DE BAGAÇO DE CANA ATRAVÉS DA TÉCNICA DE COAGULAÇÃO E FLOCULAÇÃO}

Leonardo de Lima Noronha, Christiane Reis Fonseca*, Cássia Cavalcanti da Silva, Messias Borges Silva e Luís Fernando Figueiredo Faria

Departamento de Engenharia Química, Escola de Engenharia de Lorena, Universidade de São Paulo, CP 116, $12602-810$ Lorena - SP, Brasil

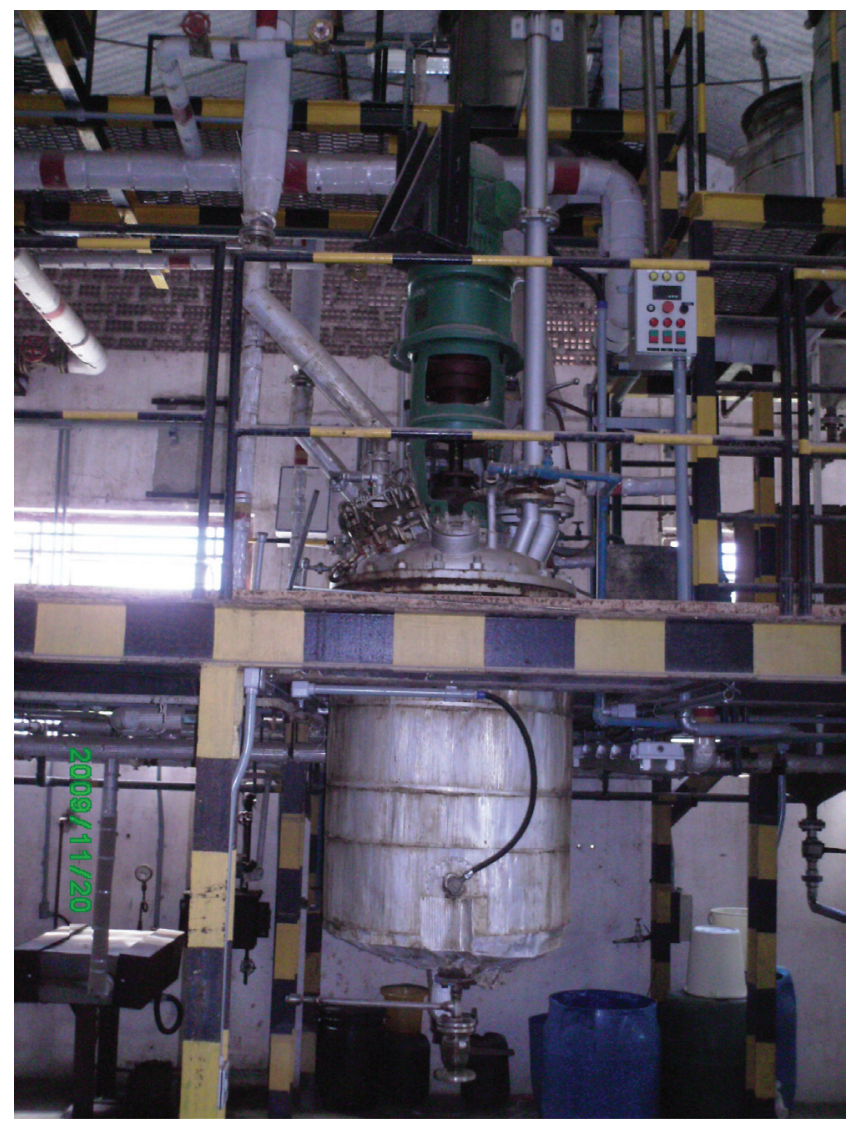

Figura 1S. Reator de aço inoxidável AISI 316

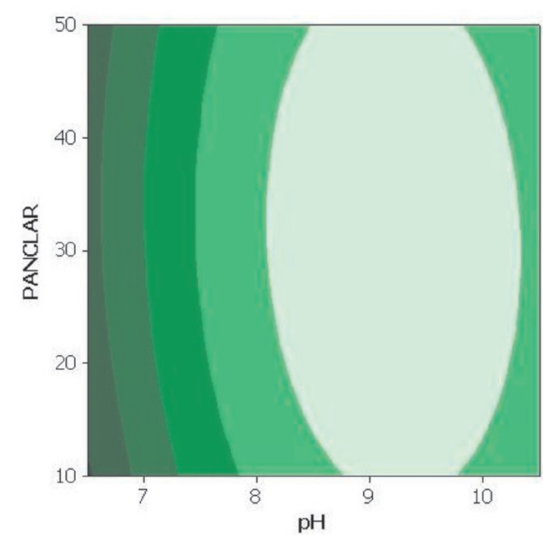

Figura 2S. Curvas de contorno em função da variação da área espectral (PANCLAR)

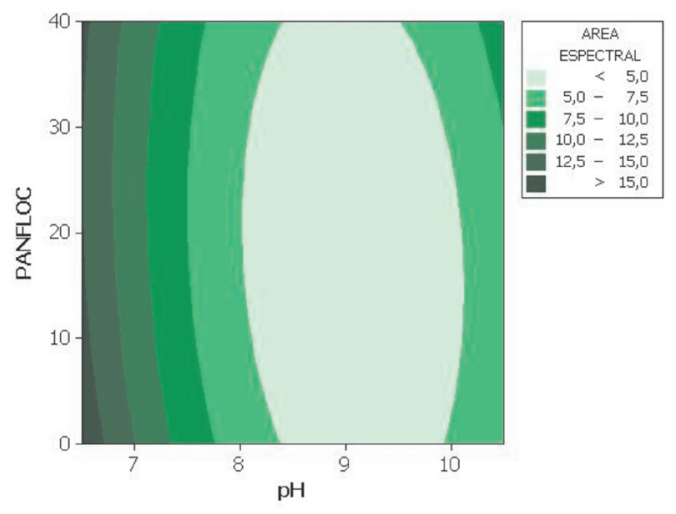

Figura 3S. Curvas de contorno em função da variação da área espectral (PANFLOC) 